\title{
Exploring the Factors Influencing Parental Choices on School Trips
}

\author{
Kornilia Maria Kotoula1*, George Botzoris², Georgia Aifantopoulou', Vassilios Profillidis² \\ ${ }^{1}$ Hellenic Institute of Transport, Centre for Research and Technology Hellas, GR57001-Thermi,Thessaloniki, P. O. B. 60361, Greece \\ 2 Section of Transportation Engineering, Department of Civil Engineering, Faculty of Engineering, Democritus University of \\ Thrace, Kimmeria Campus-Building B, 67100 Xanthi, Greece \\ * Corresponding author, e-mail: nilia@certh.gr
}

Received: 09 March 2020, Accepted: 10 November 2020, Published online: 06 April 2021

\begin{abstract}
Within the last decades, the examination and definition of factors affecting the mode choice decision on school trips has gained much of attention, as the completion of such trips represent a vast percentage of total travel demand. Key players of the decision process are students' parents, deciding how their children will complete everyday trips from their residence to the school unit and vice versa. The current study examines the factors affecting parents' travel mode choice for school trips of both primary and high school students in Thessaloniki city, Greece. Data collected is based on a questionnaire survey in which, 512 parents participated, stating their perception regarding the use of several transport modes for school trips and the motives behind specific adopted travel behavioural aspects. Three main topics are examined and analysed related to the parents' attitudes and their travel habits in the choice of motorized and non-motorized transport modes, the parents' perception regarding the built environment safety, and the parents' perception regarding specific parameters which appear to motivate them in the mode choice decision process. For the research analysis, a number of statistical methods and techniques are deployed, starting with descriptive statistical and Pearson's correlation analysis and proceeding with the exploratory and confirmatory factor analysis. The results verify initial thoughts for critical factors which appear to affect parents' choices regarding their children's school trips while they also gives an initial picture of parents' experiences regarding the school travel mode choice, in an urban environment of a typical Greek city.
\end{abstract}

\section{Keywords}

school transportation, students, travel behaviour, mobility patterns, mode choice

\section{Introduction}

During the last decade, an increasing interest in both students' mobility behaviour and mobility needs has been noticed. School transportation is an integral and important part of society including many aspects such as knowledge attainment, socialization, identity building, etc. (Kotoula et al., 2017). Even travel behaviour of children differs fundamentally from that of adults (McMillan, 2005), the mode choice decision process for school trips remains unclear. The examination and definition of factors affecting the mode choice decision on school trips, is a rather essential issue, for a variety of reasons.

First of all, the completion of such everyday trips represents a significant percentage of the total travel demand. Therefore, the monitoring of these trips needs to be considered in all relevant traffic studies and traffic models used for the simulation of traffic patterns and for the production of realistic predictions regarding the traffic profile of the study area (Profillidis and Botzoris, 2018). Moreover, within the last decades an increase of the population of school age groups at international level has been noticed. As a related study reports (United Nations, 2019), almost one quarter $(26.6 \%)$ of the total population consists of children aged 5-19 years old. In this context, the understanding of students' behaviour regarding their travel habits is critical in order to examine and solve problems related to traffic congestion around school units during morning and afternoon hours, road accidents, low safety conditions, etc. Additionally, it is very important to understand the critical factors influencing the mode choice process in young age groups, as experiences gained at young ages influence travel decisions made in adulthood (Mackett, 2001). Finally, as it has been noticed, students' travel behaviour 
has substantially changed over the last years, the most striking changes being probably the shift from alternative modes such as walking and cycling to the use of private vehicle (McDonald, 2007; Shaw et al., 2013; Broberg et al., 2013; Mitra et al., 2016). Understanding the motives behind this shift may lead to the design of actions promoting the use of more sustainable modes in school trips, inverting this trend.

The key players of the whole decision process are students' parents, as in most cases school trips of young students are decided solely by them. Children have limited scope of how to travel and they are more dependent on their parents' decision (Mackett, 2013, Yarlagadda and Srinivasan, 2008), unlike university students who form a social group essentially autonomous in terms of mode choice decision making (Kotoula et al., 2018). As school travel is directly linked to temporal and spatial constraints of parents, students' mobility, especially at young ages, depends solely on the availability and daily schedule of their guardians.

Taking into account the above, the current study examines the factors affecting parents' travel mode choice for school trips of both primary and high school students in the city of Thessaloniki (Greece). The collected data is based on a questionnaire survey where in total 512 parents participate, stating their perception regarding the use of several transport modes for school trips and the motives behind specific adopted travel behavioural aspects. Three main topics are examined and further analysed related to the parents' attitudes and their formed travel habits towards motorized and non-motorized transport modes, the parents' perception regarding the built environment safety, and the parents' perception regarding specific parameters appear to motivate them in the mode choice decision process. For the research analysis, a number of statistical methods and techniques are deployed, starting with descriptive statistical and Pearson's correlation analysis and proceeding with the exploratory and confirmatory factor analysis. The results verify initial thoughts for critical factors appear to affect parent's choices regarding their children school trips while also shape a first picture of parents' experiences regarding the school travel mode choice.

\section{Factors affecting mode choice behaviour}

In recent years numerous studies can be found to have investigated the factors affecting parents' mode choice on school trips. The selection of private vehicle, school bus or active transport modes such as walking and bicycling for the completion of such trips are found to be affected by a wide range of factors:
- parents' and students' demographic and socio-economic characteristics,

- parents' attitudes and perceptions,

- built environment characteristics, and

- trip safety.

The results of some surveys are described below.

McMillan et al. (2006) examined whether the student's gender and age influence the mode choice decision. The survey was conducted in 16 schools in California and in total 1244 parents participated. According to the results, boys are more likely to use alternative transport modes but in case parents have adopted sustainable behavioural patterns, gender plays no crucial role in the mode choice process decision. Using the same data one year later, McMillan (2007) found out that the urban environment as well as other factors such as neighbourhood safety and traffic safety are similarly important.

In 2006, Timperio et al. examined the correlation of several personal, social and environmental factors with walking and bicycling, as well as parental perceptions regarding the trip's safety. A busy road network, lack of green lights throughout the whole route and the fact that there are few other students in the neighbourhood were negatively correlated with non-motorized transportation.

Noland et al. (2014) used a sample of 1573 students (5-13 years old) confirming that speed limits, existence of open public spaces and parks, adequate sidewalk infrastructure and good connectivity are correlated in the choice of walking.

Mandic et al. (2015) conducted a survey in 22 out of 24 school units in Otago (New Zealand) examining personal, social and environmental factors, including the distance from/to school, leisure time for socialization and number of personal computers (PCs) per household. Multivariate binary logistic regression models concluded that, compared to private vehicle users, others who lived shorter distances from school were more likely to present a lower car ownership index while the number of personal computers per household was also low. The lack of PCs in students' households was directly related to the free time each student had for socialization. As concluded, these students preferred to walk to and from school as they felt they were given more opportunities for socialization.

Mitra and Buliung (2015) conducted research between two age groups (11 years old and 14-15 years old) in Toronto. A multivariate logit model was used to analyse the results. As concluded, younger students tend to choose a school bus for their trip, while the older ones prefer 
to use public transport systems. In case, parents are not available to accompany students of both age groups, alternative transport modes are adopted; otherwise students are driven to school by their parents.

Murtagh et al. (2016) examined factors influencing the mode choice decision on school trips, conducting the same survey in Ireland twice over a four year period and using the same sample. More specifically, the survey was initially conducted on 8658 parents of nine-year-old students and after four years the same survey was repeated in the same sample with active responses of 7400 parents of students. The transport modes examined were categorized to non-motorized (walking, bicycling) and motorized transport modes. The analysis performed came to the following conclusions: distance is one of the most important factors in non-motorized transport; a distance change between the student's residence and the school unit does not affect the maintenance and adoption of non-motorized transport modes; students living within the urban environment are those adopting sustainable behavioural habits while those living in rural areas and were accustomed to travel by motorized transport modes, continued doing so after four years.

Rothman et al. (2016) investigated whether walking to and from school is related to parents' perception regarding the safety level provided by the route as well as the association of various characteristics of built environment. The research was conducted in Toronto (Canada) in 20 primary schools and involved parents of students aged 4 to 6 years old. In total 733 parents participated in the questionnaire survey. Logistic regression analysis led to the conclusion that parents expressing their concerns about the danger of walking to/from school were most likely those who would not allow their children to walk to school. Regarding the built-environment characteristics as found out, the presence of dangerous crossings nearby school units as well as the high frequency of traffic lights were directly related to the high degree of danger of a walking trip.

Hatamzadeh et al. (2017) used a sample from the origin-destination survey conducted in the context of the 2007 traffic study in Iran. Trips related to school transportation were isolated and further analyzed. In total the sample consisted of 1411 elementary school students, 1416 high school students (12-15 years old) and 1409 high school students (16-18 years old). To analyze the results, three different binary logistic models were developed, one for each age group, in order to identify the factors that increase the choice of walking to and from school within the urban environment. The analysis showed that age differentiated the students' mobility and gender played important role, as girls of all groups were less likely to walk in comparison with boys.

Zhang et al. (2017) used a sample from the origin-destination survey conducted in the context of the 2014 traffic study in Beijing. The questionnaire survey included 40,003 households. Trips related to school transportation were isolated and further analyzed. In total, the sample consisted by 4580 school students (7-18 years old). A treebased regression model and a logit-based regression model were used to analyze the results. In conclusion, the existence of private vehicles in the household, inadequate pedestrian and bicycle infrastructure and the negative attitude of adults to accompany students to their school units, intensified the use of motorized transport modes.

A review of the samples and methodologies used in various surveys of parents' mode choice decision on school trips is presented in Table 1 .

\section{Research design}

The current research tries to identify factors affecting parents' mode choice decision on school trips in the city of Thessaloniki, the second-largest city in Greece with over one million inhabitants in its metropolitan area. Based on the literature review findings a questionnaire survey was designed and conducted. The survey addressed parents of both public primary and high school students.

The first part includes questions regarding the parents' socio-demographic characteristics (age, gender, educational level, car ownership, etc.) as well as the students' personal characteristics (age and gender).

Section 2 includes questions regarding the students' school unit (school name, municipality, whether the school unit's environment is urban or suburban and the distance from the student's residence). Also Section 2, the transport mode chosen by the parents for their children everyday school trips is required, as well as the mode they would prefer for their children to use under different circumstances. Finally, there are some additional questions regarding the willingness of students to bike to school and the willingness of parents to permit their children to walk or bike to school.

Section 3 is structured under three sub-sections. In the first one, eighteen crucial factors that motivate parents in the mode choice decision process are given in order the level of significance to be defined. For that purpose a typical 5-level Likert scale is used (1 corresponds to very significant, 5 corresponds to not significant at all). Then, 
Table 1 Literature findings regarding parent's mode choice decision on school trips

\begin{tabular}{|c|c|c|c|c|}
\hline Researchers and country & $\begin{array}{l}\text { Sample (number of } \\
\text { students) }\end{array}$ & $\begin{array}{l}\text { Transport modes under } \\
\text { study }\end{array}$ & $\begin{array}{l}\text { Aspects examined and } \\
\text { analyzed }\end{array}$ & Methods \\
\hline McMillan et al. (2006), USA & $\mathrm{n}=1244(11-13$ years old $)$ & $\begin{array}{c}\text { Private vehicle, walking, } \\
\text { bicycling }\end{array}$ & Gender, age & $\begin{array}{l}\text { Logit probability } \\
\text { models }\end{array}$ \\
\hline McMillan (2007), USA & $\mathrm{n}=1244(11-13$ years old $)$ & $\begin{array}{c}\text { Private vehicle, walking, } \\
\text { bicycling }\end{array}$ & $\begin{array}{l}\text { Urban environment, } \\
\text { levels of safety } \\
\text { (neighbourhood and } \\
\text { traffic safety) }\end{array}$ & $\begin{array}{l}\text { Logit probability } \\
\text { models }\end{array}$ \\
\hline Timperio et al. (2006), Melbourne, Australia & $\mathrm{n}=677(10-12$ years old $)$ & Walking, bicycling & $\begin{array}{l}\text { Road safety, traffic } \\
\text { (concerns for } \\
\text { strangers), public } \\
\text { transport availability, } \\
\text { need for crossing } \\
\text { several roads }\end{array}$ & Odds ratios \\
\hline Noland et al. (2014), New Jersey, USA & $\mathrm{n}=1573(5-13$ years old $)$ & $\begin{array}{l}\text { Private vehicle, school } \\
\text { bus, walking }\end{array}$ & $\begin{array}{l}\text { Speed limits, existence } \\
\text { of open public spaces, } \\
\text { length of sidewalks }\end{array}$ & Mixed logit model \\
\hline Mandic et al. (2015), New Zealand & $\mathrm{n}=2018$ & $\begin{array}{l}\text { Private vehicle, bus, } \\
\text { walking, bicycling }\end{array}$ & $\begin{array}{c}\text { Distance, car } \\
\text { ownership, leisure } \\
\text { time for socialization, } \\
\text { number of personal } \\
\text { computers in the } \\
\text { household }\end{array}$ & $\begin{array}{c}\text { Multivariate } \\
\text { binary logistic } \\
\text { regression models }\end{array}$ \\
\hline Mitra and Buliung (2015), Toronto, Canada & $\mathrm{n}=165(6-11$ years old $)$ & $\begin{array}{l}\text { School bus, walking, } \\
\text { bicycling }\end{array}$ & $\begin{array}{l}\text { Distance reduction, } \\
\text { road safety } \\
\text { enhancement, } \\
\text { availability of } \\
\text { infrastructure for } \\
\text { walking and bicycling }\end{array}$ & $\begin{array}{l}\text { Binomial logistic } \\
\text { regression models }\end{array}$ \\
\hline Murtagh et al. (2016), Ireland & $\begin{array}{l}\mathrm{n}=8502(9 \text { years old }) \\
\mathrm{n}=7479(13 \text { years old })\end{array}$ & Walking, bicycling & $\begin{array}{c}\text { Distance, suburban } \\
\text { areas, low/high traffic } \\
\text { volumes }\end{array}$ & $\begin{array}{l}\text { Chi square } \\
\text { Cramer's V }\end{array}$ \\
\hline Rothman et al. (2016), Toronto, Canada & $\mathrm{n}=733(10-12$ years old $)$ & Walking & $\begin{array}{l}\text { Route safety build } \\
\text { environment } \\
\text { characteristics }\end{array}$ & $\begin{array}{l}\text { Logistic } \\
\text { Regression } \\
\text { models }\end{array}$ \\
\hline Hatamzadeh et al. (2017), Raat, Iran & $\begin{array}{c}n=1411(6-12 \text { years old }) \\
n=1416(13-15 \text { years old }) \\
n=1409(16-18 \text { years })\end{array}$ & Walking & Age, gender, distance & $\begin{array}{l}\text { Binary logistic } \\
\text { models }\end{array}$ \\
\hline Zhang et al. (2017), Beijing, China & $\mathrm{n}=4580(7-18$ years old $)$ & $\begin{array}{l}\text { Walking, bicycling, } \\
\text { private vehicle, bus, } \\
\text { metro }\end{array}$ & $\begin{array}{c}\text { Distance, car } \\
\text { ownership, lack of } \\
\text { infrastructure for } \\
\text { walking and bicycling }\end{array}$ & $\begin{array}{l}\text { Tree-based } \\
\text { regression model, } \\
\text { logit-based } \\
\text { regression model }\end{array}$ \\
\hline
\end{tabular}

in the second sub-section, the role of the structure environment in which students travel is examined. Parents are asked to declare their level of agreement or disagreement regarding 13 statements describing the environment that includes the route from the residence to the school unit. Once again a 5-level Likert scale is used for that purpose (1 corresponds to strongly agree, 5 corresponds to strongly disagree). The questionnaire is completed in the third sub-section where fifteen statements related to parents' travel habits are examined in order to identify the impact of their perception regarding the different means of transport on the school trips mode choice process.

The survey took place from May 2019 to June 2019 and from September 2019 to November 2019. In total 512 questionnaires were completed. The minimum sample size was defined based on the following statistical method (Johnson and Wichern, 1992; Profllidis and Botzoris, 2018): 


$$
n \geq N \cdot\left[1+\frac{N-1}{p \cdot(1-p)} \cdot\left(\frac{d}{z_{a / 2}}\right)^{2}\right]^{-1}
$$

where:

- $\mathrm{N}$ : the number of total population.

- $\mathrm{n}$ : size of sample, the number of individuals required in order the required level of precision to be achieved.

- $\mathrm{p}$ : a probability parameter estimating the chance that the sample contains a specific characteristic. Parameter $p$ is an estimation of the proportion of individuals (with a specific characteristic) falling into the group we are interested in within the population. If no previous experience exists, then a value $\mathrm{p}=50 \%$ is considered as the worst case.

- $\mathrm{d}$ : the acceptable error that we are willing to accept or tolerate (in our research $\pm 5 \%$ ). It describes how close the answer of the sample is to the true value of the population. The smaller the margin of error is, the closer the findings of the survey are to the reality.

- $\mathrm{z}_{\alpha / 2}$ : parameter related to the confidence level which measures how certain we can be that the sample reflects the population, within the acceptable error $\mathrm{d}$. It takes the value 1.96 for confidence level $95 \%$.

Based on Eq. (1) for the case examined, and due to the fact that in the study area the number of primary and high school students is estimated around 100,000, in total 512 questionnaires were completed and further analyzed.

\section{Research analysis}

For the research analysis a number of statistical methods and techniques are adopted. The statistical approach starts with the descriptive statistical analysis and the Pearson's correlation analysis. It proceeds with the Exploratory (EFA) and Confirmatory Factor Analysis (CFA).

Statistical descriptive analysis mainly investigates the frequency of respondents' responses, as the questionnaire items are represented by categorical and scale questions. The use of Pearson's correlation analysis intends to detect correlations between the variables in order the EFA to be supported. The EFA intends to group the variables into factors. Their validity is subsequently ascertained through the CFA and the reliability analysis through the Cronbach's alpha coefficient estimation.

\section{Results}

\subsection{Parents' and students' profile}

Regarding the respondents' gender, the $1 / 3$ are men $(33.5 \%)$. The sample includes all age groups, with the $2 / 3$ of respondents belonging to the age group of 40-49 years old. The majority of participants $(99.2 \%)$ are married or formally cohabitating. With regards to the level of education, the percentage of those holding a bachelor degree is $35.2 \%$.

In terms of employment status, $85.4 \%$ of the respondents are full-time employees. Both parents (78.5\%) present a very high percentage of having driving license. However, this percentage does not predict that both parents own or drive a car. In addition, the average value for car ownership index is estimated at 1.55 vehicles/household. Regarding the student's gender, $54.1 \%$ are girls while the remaining $45.9 \%$ are boys. The average number of children in families is estimated at $1.46 \pm 0.51$ children and the mean age at $11 \pm 3.2$ years. Lastly, the student's school units are located in urban areas $(73 \%)$ while the remaining $27 \%$ are located in suburban areas.

\subsection{Descriptive statistical investigation of scale questions}

Fig. 1 depicts the distance of students' residence to the school unit. As shown, $60.7 \%$ of students live in a distance less than $1 \mathrm{~km}, 38.3 \%$ in less than 500 meters and the remaining $22.4 \%$ in a distance ranging from 500 meters to $1 \mathrm{~km}$. The percentage for students living in distances between 1.5 $\mathrm{km}$ to $3 \mathrm{~km}$ is quite low (11.5\%). However, the $13.5 \%$ of students are found to live in a distance more than $3 \mathrm{~km}$ from the school unit, a fact that probably prohibits them to walk to school. This may be one of the reasons that $16.4 \%$ of parents state their child has expressed the desire to bike to school. Regarding the parents' willingness to allow their children walk or bike to school all by themselves, $46.6 \%$ and $21.8 \%$ totally disagree or disagree, while the remaining $11.6 \%$ and $26.2 \%$ totally agree or agree.

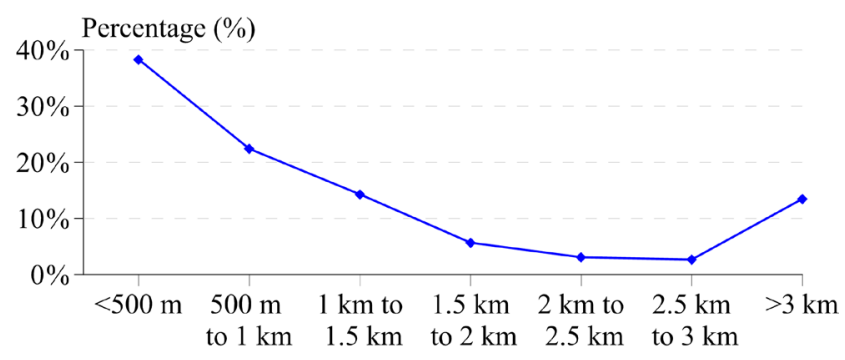

Fig. 1 Distance of residence to the school unit 
Interest can be found regarding the parents' responses about the current transport mode used for the school transportation and the one they would prefer to use in case of different circumstances. Frequencies of responses indicate a large difference between the current transport mode choice and the preferred one, as depicted in Table 2. The most significant difference is noticed regarding the option "I drive him/her to school". While $42.4 \%$ of parents choose private vehicle for the completion of the school trip, only the $11.1 \%$ would prefer to use it if circumstances were different. The $31.3 \%$ difference corresponds to the $1 / 3$ of the sample and it seems to be allocated to the preferable option of walking with friends (13.3\% increase) and use of school bus paid by the school unit (12.6\% increase).

Regarding the frequencies of elements depicted in Table 3, these are related to the level of significance parents attribute to variables that according to the literature review are found to motivate them in the mode choice decision process.

According to the results, safety is the predominant factor as $56.9 \%$ and $25.5 \%$ rate it as very significant and significant. Furthermore, students' age and distance from the school unit play also a crucial role in parents' motivation to use specific mode for their children school trip. Travel time, parents' working hours are also important, while the gender, the income and the travel cost appear to be the motivation factors that are considered as the least not significant.

Regarding the statements related to the safety of built environment, the majority of parents (79\%) agree that "There are no adequate infrastructures to protect a cyclist". A high percentage of parents (56.5\%) agree with the statement that "Residences in the neighbourhood are

Table 2 Current and preferable transport mode for the school transportation trip completion

\begin{tabular}{lccc}
\hline $\begin{array}{l}\text { Transport mode options - } \\
\text { residence to school trip }\end{array}$ & $\begin{array}{c}\text { Current } \\
\text { choice }\end{array}$ & $\begin{array}{c}\text { Preferable } \\
\text { choice }\end{array}$ & Difference \\
\hline Walking, alone & $10.0 \%$ & $11.1 \%$ & $1.1 \%$ \\
Walking, with friends & $15.6 \%$ & $28.9 \%$ & $13.3 \%$ \\
$\begin{array}{l}\text { Walking, accompanied by the } \\
\text { respondent }\end{array}$ & $16.0 \%$ & $18.2 \%$ & $2.2 \%$ \\
$\begin{array}{l}\text { Walking, accompanied by an } \\
\text { adult }\end{array}$ & $5.8 \%$ & $5.3 \%$ & $-0.5 \%$ \\
$\begin{array}{l}\text { Urban bus } \\
\text { School bus, paid by school }\end{array}$ & $2.0 \%$ & $3.6 \%$ & $1.6 \%$ \\
I drive him/her to school & $42.4 \%$ & $11.1 \%$ & $-31.3 \%$ \\
$\begin{array}{l}\text { A friend of mine drives him/ } \\
\text { her to school }\end{array}$ & $1.0 \%$ & $0.0 \%$ & $-1.0 \%$ \\
Bicycle & $0.0 \%$ & $2.0 \%$ & $2.0 \%$ \\
Taxi & $0.0 \%$ & $0.0 \%$ & $0.0 \%$ \\
\hline
\end{tabular}

in good condition" and $46.2 \%$ agree or strongly agree that "There are no vandalism trails in the neighbourhood". Parents seem to keep a rather neutral position regarding the statement "The neighbourhood where students travel is safe", while their perception regarding the sidewalks safety is rather negative.

Finally, the analysis of the fifteen statements related to parents' perceptions on different transport modes indicates that in their large majority parents are not satisfied with time consistency and comfort of the provided urban transport services (Fig. 2). As for the statement "I believe the urban bus is a reliable transport mode", $56.6 \%$ disagree, while almost $50 \%$ of the sample avoids using it for trips within the city.

Regarding the private vehicle use, high percentages $(80.4 \%)$ of disagreement are noticed related to the statement "Traffic congestion does not bother me", while also $91.3 \%$ of parents agree that "Driving to school contributes to traffic congestion". As for the statement "Car ownership is a symbol of prestige", only $14.5 \%$ of the sample agrees. Although almost $73 \%$ of parents state that owning a car makes their everyday life easier, only $29.3 \%$ state they like to drive to any destination within the city. In addition, $40.7 \%$ of the sample disagrees that driving is more comfortable than walking or bicycling, while $30.7 \%$ appears to maintain a neutral position. Finally, most parents $(57.7 \%)$ agree that "Students driven by car to school are more possible to be dependent on it".

Regarding the parents' perception related to the bicycle use, $91.4 \%$ state "I would prefer my child to walk or bike to school under different circumstances", while over $88.3 \%$ agree and strongly agree with the statement that "Walking or cycling to school increases students' physical activity". Finally, $16.6 \%$ strongly agree and $63.9 \%$ agree that "Walking or bicycling to school is a good way to be familiar with the built environment".

\subsection{Exploratory Factor Analysis}

The Exploratory Factor Analysis (EFA) was initially adopted to investigate and identify the factors (latent variables) that the 49 observed variables (questionnaire items) may form. Initially, the variables were tested regarding their correlations (use of Pearson coefficient). The results showed that there is a large number of statistically significant correlations making it possible to group the variables into factors.

Due to the high correlation between the two items representing the preferred mode of transport (residence to school and school to residence), only one was used in 
Table 3 Frequencies related to certain factors' significance

\begin{tabular}{|c|c|c|c|c|c|c|c|}
\hline & Not significantat all & Not significant & Neutral & Significant & Verysignificant & Mean & Standard deviation \\
\hline Gender & $27.5 \%$ & $23.4 \%$ & $26.7 \%$ & $17.7 \%$ & $4.7 \%$ & 2.49 & 1.20 \\
\hline Age & $5.3 \%$ & $7.9 \%$ & $7.1 \%$ & $32.4 \%$ & $47.3 \%$ & 4.09 & 1.15 \\
\hline There is someone to help me & $10.2 \%$ & $17.7 \%$ & $13.9 \%$ & $32.8 \%$ & $25.4 \%$ & 3.45 & 1.25 \\
\hline Working hours & $8.4 \%$ & $11.6 \%$ & $11.6 \%$ & $34.4 \%$ & $34.0 \%$ & 3.74 & 1.20 \\
\hline Income & $20.9 \%$ & $23.9 \%$ & $30.4 \%$ & $16.0 \%$ & $8.8 \%$ & 2.68 & 1.22 \\
\hline Driving license possession & $17.1 \%$ & $18.5 \%$ & $22.6 \%$ & $26.3 \%$ & $15.5 \%$ & 3.05 & 1.17 \\
\hline Car ownership & $16.5 \%$ & $18.3 \%$ & $18.8 \%$ & $29.5 \%$ & $16.9 \%$ & 3.12 & 1.24 \\
\hline Limitations on parking & $15.9 \%$ & $19.4 \%$ & $21.9 \%$ & $28.5 \%$ & $14.3 \%$ & 3.06 & 1.30 \\
\hline Distance from school & $5.3 \%$ & $8.8 \%$ & $10.0 \%$ & $36.3 \%$ & $39.6 \%$ & 3.96 & 1.15 \\
\hline Time spent on trip & $7.5 \%$ & $8.8 \%$ & $11.6 \%$ & $44.4 \%$ & $27.7 \%$ & 3.76 & 1.17 \\
\hline Trip cost & $21.6 \%$ & $17.5 \%$ & $30.9 \%$ & $21.2 \%$ & $8.8 \%$ & 2.78 & 1.25 \\
\hline Student's comfort & $7.3 \%$ & $8.4 \%$ & $19.5 \%$ & $36.5 \%$ & $28.3 \%$ & 3.69 & 1.20 \\
\hline Student's safety & $6.7 \%$ & $5.1 \%$ & $5.8 \%$ & $25.5 \%$ & $56.9 \%$ & 4.21 & 1.18 \\
\hline Environmental sensitivities & $12.6 \%$ & $15.3 \%$ & $31.2 \%$ & $28.5 \%$ & $12.4 \%$ & 3.13 & 1.19 \\
\hline Student's health & $9.4 \%$ & $9.4 \%$ & $22.0 \%$ & $32.9 \%$ & $26.3 \%$ & 3.57 & 1.24 \\
\hline School luggage (heavy or not) & $10.0 \%$ & $7.8 \%$ & $19.0 \%$ & $35.8 \%$ & $27.4 \%$ & 3.63 & 1.24 \\
\hline Socializing with friends & $9.2 \%$ & $9.4 \%$ & $22.2 \%$ & $36.5 \%$ & $22.7 \%$ & 3.54 & 1.20 \\
\hline $\begin{array}{l}\text { Spending quality time with } \\
\text { my child }\end{array}$ & $11.5 \%$ & $19.2 \%$ & $30.6 \%$ & $26.4 \%$ & $12.3 \%$ & 3.09 & 1.19 \\
\hline
\end{tabular}

I am satisfied with the time consistency of the urban bus services

I am satisfied with the comfort of the urban bus

The urban bus is a very reliable transport mode

I like to use the urban bus for travelling within the city

Traffic congestion doesnt bother me Car ownership is a symbol of prestige

I use my car even for short distances

Owning a car makes my life more comfortable

I like driving in the city
Driving is more comfortable than walking/cycling

\begin{tabular}{|l|l|l|l|l|l|}
\hline & 74.7 & 14.1 & 11.2 \\
\hline
\end{tabular}

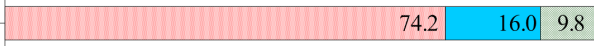

\begin{tabular}{|l|r|r|r|r|}
\hline 17 & 56.6 & 24.0 & 19.4 \\
\hline
\end{tabular}

Driving to school contributes to traffic congestion

Driving my child to school may lead to car use addiction in the future
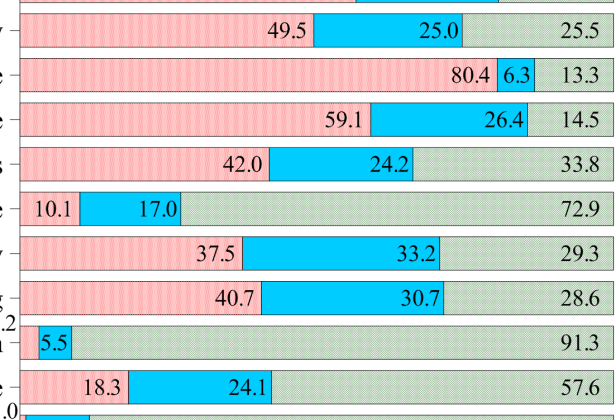

Travelling to school on foot or by bike is a way to increase my childs physical activity -

I would like my child to travel to school on foot or by bike under the appropriate circumstances

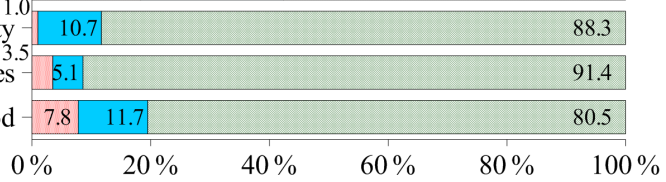

Fig. 2 Cumulative frequencies regarding parents' attitudes towards motorized and non-motorized transport modes 
the analysis. Regarding the EFA, principal axis factoring method was deployed using the direct oblimin rotation technique (Table 4). This technique was used as high correlations $(>0.32)$ in more than $10 \%$ were found in the factor matrix when the varimax rotation technique was initially applied (Tabachnick and Fidell, 2007).

Of the 49 variables, only eight were not included in the factors as their weights found to be less than 0.05 . The travel costs and family income variables, presented high weights and created a factor. However, they were excluded from further analysis, as two variables are not considered sufficient to generate one factor. The other six variables that were not included in the final factor analysis due to their low factor loadings were: student's gender, lack of appropriate infrastructure for cyclists, student's dependency on car if used to be driven by private vehicle to school, traffic congestion caused by parents driving their children to school, the fact that car ownership may be a symbol of prestige, and the fact that traffic congestion does not bother the parent.

The Kaiser-Meyer-Olkin index concerning the sampling adequacy was high (0.864), and the Bartlett test concerning the homogeneity of variances across factors was statistically significant $(\mathrm{p}<0.001)$ indicating that factor analysis can be applied to the data sample (Hair et al., 2010).

The rotation technique identified 9 factors with eigenvalues greater than 1 which include variables with factor loadings greater than 0.5 (Table 4). The scree plot also confirmed the existence of nine factors. These nine factors account for $61 \%$ of the total variation of data (Table 4 ). The factors were labelled based on the conceptual framework of variables. The seven items (variables) included in the first factor are all related to the parent's motivation to select a transport mode for the school trip (MOTMODE). The second factor includes five items all associated to parent's motivation to select a transport mode regarding the child's physical and mental health (MOTHEALTH). The third factor incorporates four items regarding the parent's attitude towards the use of urban bus (ATTBUS). The fourth factor is the mode choice dependent variable (MODE). The fifth factor is related to the parent's attitude towards the use of private vehicle (ATTCAR), while the sixth one appeared to manifest the parent's attitude towards walking and bicycling (ATTWLKBIK). The seventh factor pertains to the motivation of parents with regard to the use of car (MOTCAR). The penultimate factor includes items all related to neighbourhood safety (NEIGBSAF), and the last factor includes items related to sidewalks and route safety (ROUTESAF), (Table 4).

\subsection{Confirmatory Factor Analysis}

The Confirmatory Factor Analysis (CFA) was used to investigate the variables' validity and to define the measurement model of the current study (Fig. 3).

Covariance between the latent variables and between the errors (e) of the observed variables were allowed and found to be statistically significant (Table 5). To evaluate the overall fit of the model the following goodness-of-fit indices were employed: chi-square/d.f. ratio, Tucker-Lewis Index (TLI), Comparative Fit Index (CFI), Incremental Fit Index (IFI) and the Root Mean Square Error of Approximation (RMSEA). As pointed out by Anderson and Gerbing (1988) researchers should adopt more than one index, whereas Kline (1998) underlined that a researcher can use five indices to assess the fit of the model to the data. The minimum required values of TLI, CFI, IFI for a good fit is 0.90 , while for chi-square/d.f. a value less than 3 is considered acceptable (Byrne, 2010). Concerning the RMSEA, values less than 0.08 and 0.05 indicate satisfactory and good fit respectively (Byrne, 2010).

In current research, the estimated values of CFI and IFI were found to be equal to 0.908 , while the corresponding value for TLI was calculated equal to 0.897 . The chisquare/d.f. ratio of 2.636 was below the threshold value of 3 and the RMSEA of 0.057 indicated a satisfactory fit of the model. Thus, the estimated fit indices have shown that the model fits the data adequately. Overall, the CFA results ensured the unidimensionality of the latent constructs.

To further evaluate the model's adequacy, reliability analysis was performed through Cronbach's alpha (Table 6). All values were above 0.70 and therefore none of them should be eliminated indicating the high homogeneity of the variables and their correspondence to the relative factor.

\section{Results}

During the last decades, the use of motorized transport modes for the completion of everyday school trips have increased, while walking and bicycling have experienced a dramatic reduction. Students' parents are called to decide the transport mode used for their children school trips. Based on an extensive literature review, a conceptual model (Fig. 4) was defined focusing on critical factors appear to affect students' commuting to school; built environment safety, parents' travel habits and parents' motivation regarding the mode choice decision were interconnected and further examined.

For the research needs, a questionnaire survey took place in the city of Thessaloniki (Greece) combining 
Table 4 Exploratory factor analysis results

\begin{tabular}{|c|c|c|c|c|c|c|c|c|c|}
\hline \multirow{2}{*}{ Variables } & \multicolumn{9}{|c|}{ Factors } \\
\hline & 1 & 2 & 3 & 4 & 5 & 6 & 7 & 8 & 9 \\
\hline 1. Safety (MOTsaf) & 0.812 & & & & & & & & \\
\hline 2. Travel time (MOTtime) & 0.785 & & & & & & & & \\
\hline 3. Working hours (MOTwork) & 0.717 & & & & & & & & \\
\hline 4. There is someone to help (MOThelp) & 0.686 & & & & & & & & \\
\hline 5. Age (MOTage) & 0.681 & & & & & & & & \\
\hline 6. Convenience (MOTconven) & 0.669 & & & & & & & & \\
\hline 7. Distance (MOTdist) & 0.634 & & & & & & & & \\
\hline 8. Socialization (MOTsocial) & & 0.832 & & & & & & & \\
\hline 9. Health (MOThealth) & & 0.763 & & & & & & & \\
\hline 10. Luggage weight (MOTweight) & 0.599 & 0.754 & & & & & -0.533 & & \\
\hline 11. Environmental sensitivities (MOTenviron) & & 0.732 & & & & & & & \\
\hline 12. Quality time (MOTqualtime) & & 0.561 & & & & & & & \\
\hline 13. Satisfied with the comfort of urban bus services (MOTbuscomf) & & & 0.885 & & & & & & \\
\hline 14. Urban bus is a reliable transport mode (MOTrelbus) & & & 0.796 & & & & & & \\
\hline 15. Satisfied with time reliability of urban bus services (MOTtimerelbus) & & & 0.640 & & & & & & \\
\hline 16. I like travelling by urban bus within the city (MOTlikebus) & & & 0.618 & & & & & & \\
\hline 17. Transport mode, School - Residence (TMsr) & & & & 0.919 & & & & & \\
\hline 18. Preferable transport mode, School - Residence (PRTMsr) & & & & 0.808 & & & & & \\
\hline 19. Transport mode Residence - School (TMrs) & & & & 0.742 & & & & & \\
\hline 20.I like driving within the city (ATTlikedriv) & & & & & -0.801 & & & & \\
\hline 21. I use my car for all trips within the city (ATTusecar) & & & & & -0.660 & & & & \\
\hline 22. Driving is more comfortable than walking/bicycling (ATTcomfcar) & & & & & -0.649 & & & & \\
\hline 23. Owning a car makes my life comfortable (ATTcomfdrv) & & & & & -0.646 & & & & \\
\hline $\begin{array}{l}\text { 24. I would prefer my child to walk or bike to school under different } \\
\text { circumstances (ATTwalkbike) }\end{array}$ & & & & & & 0.704 & & & \\
\hline $\begin{array}{l}\text { 25. Walking/bicycling to school is a good way my child be familiar } \\
\text { with environment(ATTfam) }\end{array}$ & & & & & & 0.672 & & & \\
\hline $\begin{array}{l}\text { 26. Walking or cycling to school increases students' physical activity } \\
\text { (ATTphac) }\end{array}$ & & & & & & 0.640 & & & \\
\hline 27. Car ownership (MMOTcar) & & & & & & & -0.968 & & \\
\hline 28. Driving licence possession (MMOTlic) & & & & & & & -0.952 & & \\
\hline $\begin{array}{l}\text { 29. There are no parking limitations outside my home or the school } \\
\text { unit (MMOTpark) }\end{array}$ & & & & & & & -0.846 & & \\
\hline 30. There are no trails of vandalism in the neighbourhood (NEIGHvand) & & & & & & & & 0.815 & \\
\hline 31. Residences of neighbourhood are in good conditions (NEIGHcond) & & & & & & & & 0.722 & \\
\hline 32. The neighbourhood the student travels is safe (NEIGHsaf) & & & & & & & & 0.614 & 0.568 \\
\hline 33. Sidewalks have sufficient width (SIDwidth) & & & & & & & & & 0.847 \\
\hline 34. Sidewalks are clean (SIDclean) & & & & & & & & & 0.842 \\
\hline 35. Sidewalks are separated from traffic with trees (SIDprot) & & & & & & & & & 0.808 \\
\hline 36. There are no obstacles on the sidewalks (SIDobst) & & & & & & & & & 0.769 \\
\hline 37. The crossings are safe (SAFcross) & & & & & & & & & 0.766 \\
\hline 38. Traffic conditions are not dangerous for the student (SAFtraf) & & & & & & & & & 0.649 \\
\hline 39. It is unlikely my child to be harassed by others (SAFhar) & & & & & & & & 0.508 & 0.591 \\
\hline $\begin{array}{l}\text { 40. It is unlikely that my child will be injured or abducted by a stranger } \\
\text { (SAFinj) }\end{array}$ & & & & & & & & & 0.588 \\
\hline 41. Adequate traffic lights (SAFlight) & & & & & & & & 0.505 & 0.520 \\
\hline Kaiser-Meyer-Olkin index: & 0.864 & & & & & & & & \\
\hline Bartlett's test (sig): & 0.000 & & & & & & & & \\
\hline Eigenvalue: & 9.555 & 4.522 & 3.172 & 2.444 & 2.223 & 1.962 & 1.621 & 1.495 & 1.193 \\
\hline$\%$ of variance explained: & 22.42 & 10.15 & 6.849 & 5.017 & 4.422 & 3.821 & 3.197 & 2.629 & 2.024 \\
\hline
\end{tabular}




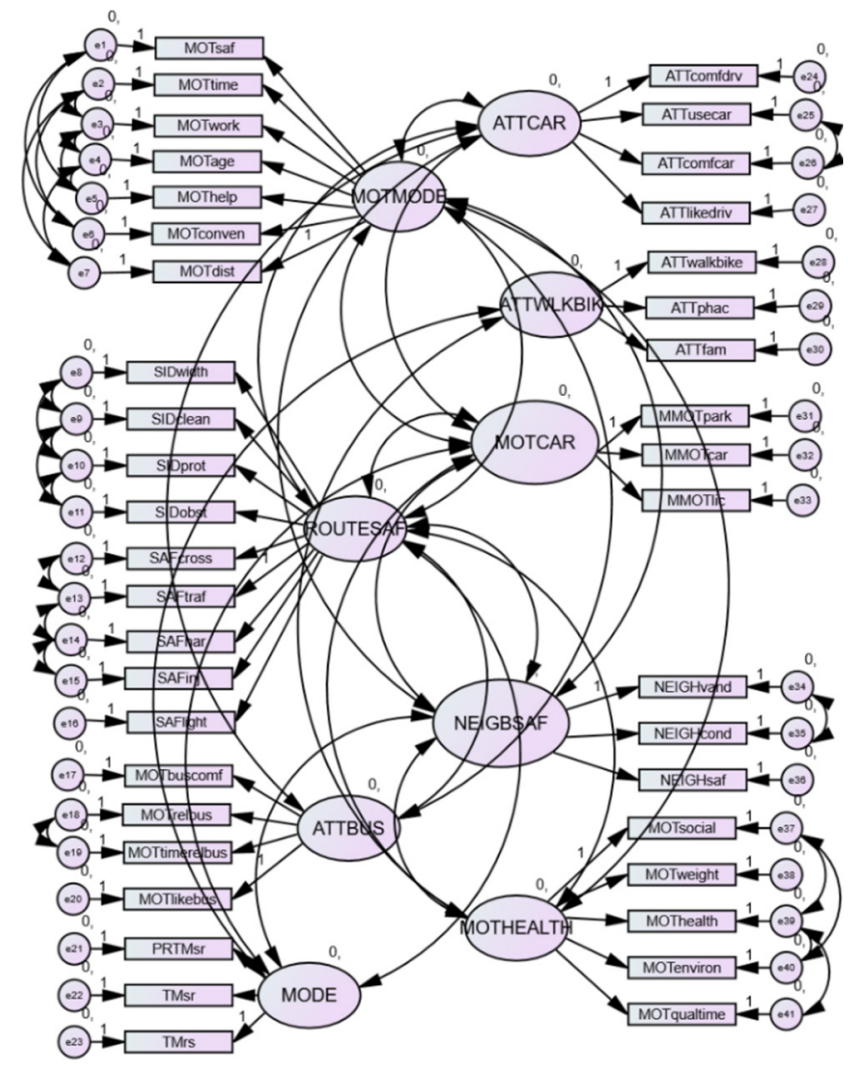

Fig. 3 Study's measurement model based on Confirmatory Factor Analysis

both primary and high school units in urban and suburban areas. In total, 512 parents participated, stating their opinion on several statements related to their travel habits, their perception regarding safety on school trips and their real motivations behind the final mode choice decision.

At first, a descriptive statistical analysis was performed, concluding that there is a crucial difference between the transport mode parents chose for their children's school trip and the one they would choose if circumstances were different. The most significant difference is noticed in the use of private vehicle which appears to be the predominant transport mode. However, the results show that a mode shift could be achieved if conditions allowed, posing walking first in the selection list and the use of hired school bus second. Regarding the significance parents attribute to several variables that seem to motivate them in the mode choice decision process, safety, student's age, distance from school, travel time and parents' working hours seem to predominate beyond other factors, while travel cost and parents' income seem to be the most not significant factors. Concerning their perception on safety provided by built environment, the lack of appropriate infrastructure for walking and cycling, seems to mostly affect their decision for not allowing their children to either walk or bike to school. In addition, parents' perception regarding the use of different transport modes seems to affect their final decision, with the inconsistency of the current urban transport system as well as the low provided comfort levels to be the two main factors affecting their negative attitude towards the use of urban bus, while it is obvious that under different circumstances the majority $(91.4 \%)$ would prefer their children to walk or bike to school, as this would increase their physical activity and would help them be familiar with the environment surrounding them. Finally, even parents use their car for everyday school trips as it is more convenient, it seems that levels of congestion caused by the exhaustive use of it discomforts them and prevents them from using it for any destination within the city.

Following, an Exploratory Factor Analysis (EFA) was applied, defining nine clustered factors including the 41 out of 49 initial observed variables (questionnaire items). The eight variables that were not included in the factors presented loading factors less than 0.05. Both the KaiserMeyer-Olkin index and Barlett test indicated that EFA could be applied in the sample of observations. The factors were named based on the conceptual framework variables represented that is:

- the parent's motivation to select a transport mode:

1. taking into account several parameters found to affect the mode choice process,

2. taking into account the student's health, and

3. taking into account elements concerning the use of private car,

- the parents' attitude towards motorized and non motorized transport modes:

1. private vehicle,

2. bus, and

3. walking and bicycling,

- the parents' perception regarding the built environment safety:

1. route safety and

2. neighbourhood safety.

Finally, the Confirmatory Factor Analysis (CFA) that we conducted created a measurement model which investigated the variables' validity and revealed both covariances between some of the factors and the some of the errors of observed variables. As a next step of the current research the development and analysis of a Structural Equation Model (SEM) is proposed for defining direct and indirect 
Table 5 Covariances significance between latent variables and errors of observed variables

\begin{tabular}{|c|c|c|c|c|c|c|}
\hline & & & Estimate & S.E. & C.R. & p. \\
\hline ROUTESAF & $\leftrightarrow$ & NEIGBSAF & 0.349 & 0.042 & 8.219 & $* * *$ \\
\hline ROUTESAF & $\leftrightarrow$ & MOTCAR & -0.231 & 0.043 & -5.423 & $* * *$ \\
\hline ROUTESAF & $\leftrightarrow$ & ATTCAR & 0.094 & 0.029 & 3.220 & 0.001 \\
\hline ROUTESAF & $\leftrightarrow$ & MODE & -0.330 & 0.065 & -5.086 & $* * *$ \\
\hline MOTMODE & $\leftrightarrow$ & NEIGBSAF & -0.087 & 0.023 & -3.797 & $* * *$ \\
\hline MOTMODE & $\leftrightarrow$ & MOTCAR & 0.354 & 0.046 & 7.756 & $* * *$ \\
\hline MOTMODE & $\leftrightarrow$ & ATTCAR & -0.072 & 0.022 & -3.282 & 0.001 \\
\hline MOTMODE & $\leftrightarrow$ & ATTBUS & -0.061 & 0.020 & -3.144 & 0.002 \\
\hline ATTCAR & $\leftrightarrow$ & NEIGBSAF & 0.103 & 0.025 & 4.086 & $* * *$ \\
\hline MOTCAR & $\leftrightarrow$ & NEIGBSAF & -0.122 & 0.034 & -3.576 & $* * *$ \\
\hline MODE & $\leftrightarrow$ & NEIGBSAF & -0.303 & 0.059 & -5.160 & $* * *$ \\
\hline MODE & $\leftrightarrow$ & MOTCAR & 0.349 & 0.076 & 4.590 & $* * *$ \\
\hline MODE & $\leftrightarrow$ & ATTWLKBIK & -0.124 & 0.049 & -2.533 & 0.011 \\
\hline ATTCAR & $\leftrightarrow$ & MOTCAR & 0.126 & 0.035 & 3.612 & $* * *$ \\
\hline ATTBUS & $\leftrightarrow$ & ATTCAR & 0.163 & 0.031 & 5.234 & $* * *$ \\
\hline ROUTESAF & $\leftrightarrow$ & ATTBUS & 0.090 & 0.022 & 4.005 & $* * *$ \\
\hline MOTMODE & $\leftrightarrow$ & ROUTESAF & -0.215 & 0.032 & -6.643 & $* * *$ \\
\hline MOTHEALTH & $\leftrightarrow$ & NEIGBSAF & -0.114 & 0.029 & -3.915 & $* * *$ \\
\hline MOTHEALTH & $\leftrightarrow$ & MOTCAR & 0.525 & 0.057 & 9.229 & $* * *$ \\
\hline MOTHEALTH & $\leftrightarrow$ & ATTWLKBIK & 0.060 & 0.020 & 2.915 & 0.004 \\
\hline MOTHEALTH & $\leftrightarrow$ & ROUTESAF & -0.215 & 0.037 & -5.764 & $* * *$ \\
\hline MOTHEALTH & $\leftrightarrow$ & MOTMODE & 0.461 & 0.050 & 9.147 & $* * *$ \\
\hline e14 & $\leftrightarrow$ & e15 & 0.519 & 0.042 & 12.354 & $* * *$ \\
\hline e9 & $\leftrightarrow$ & e8 & 0.307 & 0.035 & 8.746 & $* * *$ \\
\hline e5 & $\leftrightarrow$ & e3 & 0.377 & 0.054 & 7.002 & $* * *$ \\
\hline e7 & $\leftrightarrow$ & e2 & 0.298 & 0.039 & 7.618 & $* * *$ \\
\hline e13 & $\leftrightarrow$ & $\mathrm{e} 12$ & 0.148 & 0.033 & 4.518 & $* * *$ \\
\hline e42 & $\leftrightarrow$ & e44 & -0.087 & 0.034 & -2.565 & 0.010 \\
\hline e42 & $\leftrightarrow$ & e43 & 0.272 & 0.044 & 6.229 & $* * *$ \\
\hline e18 & $\leftrightarrow$ & e17 & 0.280 & 0.043 & 6.467 & $* * *$ \\
\hline e37 & $\leftrightarrow$ & e38 & 0.391 & 0.047 & 8.391 & $* * *$ \\
\hline e11 & $\leftrightarrow$ & e10 & 0.243 & 0.034 & 7.184 & $* * *$ \\
\hline e10 & $\leftrightarrow$ & e9 & 0.214 & 0.033 & 6.396 & $* * *$ \\
\hline e11 & $\leftrightarrow$ & e9 & 0.154 & 0.027 & 5.612 & $* * *$ \\
\hline e13 & $\leftrightarrow$ & e14 & 0.066 & 0.019 & 3.507 & $* * *$ \\
\hline e3 & $\leftrightarrow$ & $\mathrm{e} 2$ & 0.077 & 0.030 & 2.588 & 0.010 \\
\hline e5 & $\leftrightarrow$ & el & -0.069 & 0.032 & -2.136 & 0.033 \\
\hline e5 & $\leftrightarrow$ & e4 & 0.165 & 0.048 & 3.398 & $* * *$ \\
\hline e6 & $\leftrightarrow$ & el & 0.107 & 0.038 & 2.805 & 0.005 \\
\hline e7 & $\leftrightarrow$ & e4 & 0.103 & 0.035 & 2.948 & 0.003 \\
\hline e10 & $\leftrightarrow$ & e8 & 0.135 & 0.030 & 4.553 & $* * *$ \\
\hline e25 & $\leftrightarrow$ & e26 & 0.102 & 0.039 & 2.601 & 0.009 \\
\hline e40 & $\leftrightarrow$ & $\mathrm{e} 43$ & 0.258 & 0.041 & 6.293 & $* * *$ \\
\hline e40 & $\leftrightarrow$ & e42 & 0.114 & 0.038 & 3.018 & 0.003 \\
\hline e4 & $\leftrightarrow$ & e3 & 0.119 & 0.043 & 2.752 & 0.006 \\
\hline e6 & $\leftrightarrow$ & e2 & 0.062 & 0.030 & 2.035 & 0.042 \\
\hline
\end{tabular}


Table 6 Values of Cronbach's alpha for each factor

\begin{tabular}{lcc}
\hline $\begin{array}{l}\text { Number of factor and } \\
\text { label of the latent } \\
\text { variable }\end{array}$ & $\begin{array}{c}\text { Number of variables } \\
\text { in each factor }\end{array}$ & Cronbach's alpha \\
\hline 1. MOTMODE & 7 & 0.88 \\
2. MOTHEALTH & 5 & 0.88 \\
3. ATTBUS & 4 & 0.82 \\
4. MODE & 3 & 0.86 \\
5. ATTCAR & 4 & 0.87 \\
6. ATTWLKBIK & 3 & 0.72 \\
7. MOTCAR & 3 & 0.95 \\
8. NEIGBSAF & 3 & 0.76 \\
9. ROUTESAF & 9 & 0.91 \\
\hline
\end{tabular}

influences and interactions between the factors and the mode choice decision (dependent variable). The model to be developed will be based on CFA's results and will include the measurement model and the structural model.

\section{References}

Anderson, J. C., Gerbing, D. W. (1988) "Structural equation modelling in practice: A review and recommended two steps approach", Psychological Bulletin, 103(3), pp. 411-423. https://doi.org/10.1037/0033-2909.103.3.411

Broberg, A., Salminen, S., Kyttä, M. (2013) "Physical environmental characteristics promoting independent and active transport to children's meaningful places", Applied Geography, 38, pp. 43-52. https://doi.org/10.1016/j.apgeog.2012.11.014

Byrne, B. M. (2010) "Structural Equation Modelling with AMOS: Basic Concepts, Application, and Programming", Routledge, New York, NY, USA

https://doi.org/10.4324/9780203805534

Hair, J. F., Black, W. C., Babin, B. J. Anderson, R. E. (2010) "Multivariate Data Analysis", Prentice Hall, Upper Saddle River, NJ, USA.

Hatamzadeh, Y., Habibian, M., Khodaii, A. (2017) "Effective factors in walking mode choice of different age groups for school trips", Transportation Research Procedia, 25, pp. 2297-2308 https://doi.org/10.1016/j.trpro.2017.05.441

Johnson, R., Wichern, D. (1992) "Applied Multivariate Statistical Analysis", Prentice-Hall, Englewood Cliffs, NJ, USA.

Kline, R. B. (1998) "Principles and Practice of Structural Equation Modeling", The Guilford Press, New York, NY, USA.

Kotoula, K., Botzoris, G., Morfoulaki, M., Aifandopoulou, G. (2017) "The existing school transportation framework in GreeceBarriers and problems comparing to other European countries", Transportation Research Procedia, 24, pp. 385-392. https://doi.org/10.1016/j.trpro.2017.05.096

Kotoula, K. M., Sialdas, A., Botzoris, G., Chaniotakis, E., Salanova Grau, J. M. (2018) "Exploring the Effects of University Campus Decentralization to Students' Mode Choice", Periodica Polytechnica Transportation Engineering, 46(4), pp. 207-214. https://doi.org/10.3311/PPtr.1164

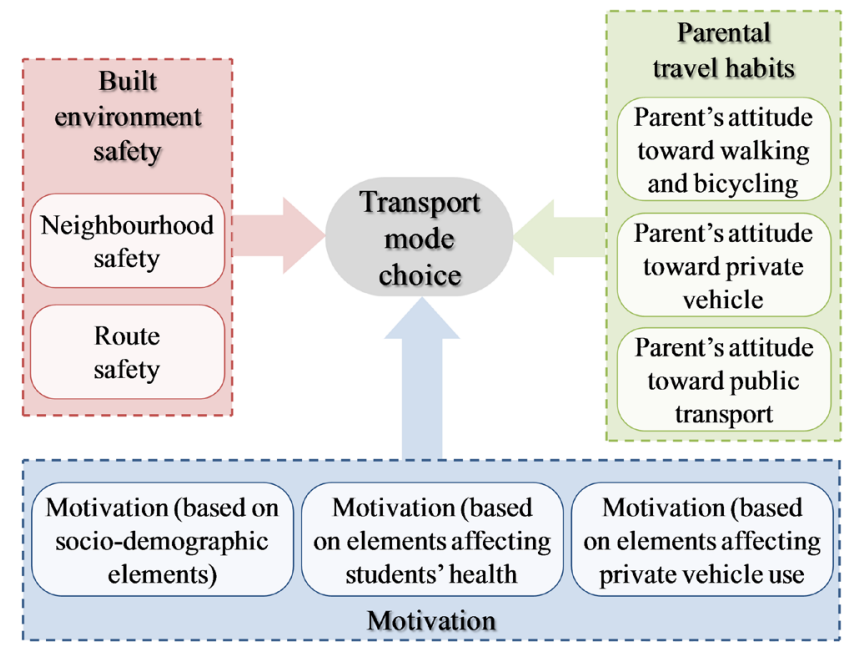

Fig. 4 Conceptual model of parents' school mode choice

Mackett, R. L. (2001) "Are we making our children car dependent?", Trinity College, Dublin, Ireland. [online] Available at: https://www. researchgate.net/publication/228809660_Are_We_Making_Our Children_Car_Dependent [Accessed: 28 February 2020]

Mackett, R. L. (2013) "Children's travel behaviour and its health implications", Transport Policy, 26, pp. 66-72. https://doi.org/10.1016/j.tranpol.2012.01.002

Mandic, S., de la Barra, S. L., Bengoechea, E. G., Stevens, E., Flaherty, C., Moore, A., Middlemiss, M., Williams, J., Skidmore, P. (2015) "Personal, social and environmental correlates of active transport to school among adolescents in Otago, New Zealand", Journal of Science and Medicine in Sport, 18(4), pp. 432-437. https://doi.org/10.1016/j.jsams.2014.06.012

McDonald, N. C. (2007) "Active Transportation to School: Trends Among U.S. Schoolchildren, 1969-2001", American Journal of Preventive Medicine, 32(6), pp. 509-516. https://doi.org/10.1016/j.amepre.2007.02.022

McMillan, T. E. (2005) "Urban Form and a Child's Trip to School: The Current Literature and a Framework for Future Research", Journal of Planning Literature, 19(4), pp. 440-456. https://doi.org/10.1177/0885412204274173

McMillan, T., Day, K., Boarnet, M., Alfonzo, M., Anderson, C. (2006) "Johnny Walks to School-Does Jane? Sex Differences in Children's Active Travel to School", Children, Youth and Environments, 16(1), pp. 75-89. [online] Available at: https://www.jstor.org/stable/10.7721/chilyoutenvi.16.1.0075 [Accessed: 28 February 2020]

McMillan, T. E. (2007) "The relative influence of urban form on a child's travel mode to school", Transportation Research Part A: Policy and Practice, 41(1), pp. 69-79. https://doi.org/10.1016/j.tra.2006.05.011

Mitra, R., Buliung, R. N. (2015) "Exploring differences in school travel mode choice behaviour between children and youth", Transport Policy, 42, pp. 4-11.

https://doi.org/10.1016/j.tranpol.2015.04.005 
Mitra, R., Papaioannou, E. M., Habib, K. M. N. (2016) "Past and present of active school transportation: An explanation of the influence of the built environment in Toronto, Canada, from 1986 to 2006", Journal of Transport and Land Use, 9(2), pp. 25-41. https://doi.org/10.5198/jtlu.2015.537

Murtagh, E. M., Dempster, M., Murphy, M. H. (2016) "Determinants of uptake and maintenance of active commuting to school", Health \& Place, 40, pp. 9-14 https://doi.org/10.1016/j.healthplace.2016.04.009

Noland, R. B., Park, H., Von Hagen, L. A., Chatman, D. G. (2014) "A mode choice analysis of school trips in New Jersey", Journal of Transport and Land Use, 7(2), pp. 111-133.

https://doi.org/10.5198/jtlu.v7i2.444

Profillidis, V. A., Botzoris, G. N. (2018) "Modeling of Transport Demand: Analyzing, Calculating, and Forecasting Transport Demand", Elsevier, Oxford, UK. https://oi.org/10.1016/C2016-0-00793-3

Rothman, L., Howard, A., Buliung, R., Macarthur, C., Macpherson, A. (2016) "Dangerous student car drop-off behaviors and child pedestrian-motor vehicle collisions: An observational study", Traffic Injury Prevention, 17(5), pp. 454-459. https://doi.org/10.1080/15389588.2015.1116041
Shaw, B., Watson, B., Frauenienst, B., Redecher, A., Jones, T., Hillman, M. (2013) "Children's independent mobility: A comparison study in England and Germany (1971-2010)", Policy Studies Institute, London, UK. [online] Available at: http://www.psi.org.uk/site/publication_detail/852/ [Accessed: 28 February 2020]

Tabachnick, B. G., Fidell, L. S. (2007) "Using Multivariate Statistics", Pearson, Boston, MA, USA.

Timperio, A., Ball, K., Salmon, J. ,Roberts, R., Giles-Corti, B., Simmons, D., Baur, L. A., Crawford, D. (2006) "Personal, Family, Social, and Environmental Correlates of Active Commuting to School", American Journal of Preventive Medicine, 30(1), pp. $45-51$.

https://doi.org/10.1016/j.amepre.2005.08.047

United Nations (2019) "World Population Prospects: Comprehensive Tables", [online] Available at: https://population.un.org/wpp/ Publications/Files/WPP2019_Volume-I_Comprehensive-Tables. pdf/ [Accessed: 28 February 2020]

Yarlagadda, A. K., Srinivasan, S. (2008) "Modeling children's school travel mode and parental escort decisions", Transportation, 35(2), pp. 201-218.

https://doi.org/10.1007/s11116-007-9144-6

Zhang, R., Yao, E., Liu, Z. (2017) "School travel mode choice in Beijing, China", Journal of Transport Geography, 62, pp. 98-110. https://doi.org/10.1016/j.jtrangeo.2017.06.001 